\title{
Consumer transition to a green economy: The role of third-party certified eco-labels
}

\author{
José Luis Vázquez ${ }^{1}$, and Ana Lanero ${ }^{1 *}$ \\ ${ }^{1}$ University of León, Department of Management and Business Economics, Campus de Vegazana s/n, \\ 24071 León, Spain
}

\begin{abstract}
In order to reduce the asymmetry of knowledge between producers and consumers, many organizations promote the use of eco-labels certified by independent third parties, with the purpose of identifying those products or services that have minor impact on the environment throughout their entire life cycle. However, since there are currently a high number of ethical labels and claims and consumers are usually confused about their real meaning. This research is intended to analyze whether consumers attribute organic properties to products identified by third-party certified eco-labels to the same extent that to other third-party certified sustainability labels and other non-certified organic claims. A survey study was carried out with a sample of 200 university business students and ANOVA analysis was used to verify differences in the meaning attributed to different labels. In general terms, the results of the study allow to conclude that consumers do not have a precise knowledge about the meaning of different sustainability dimensions certified by official seals, nor do they know how to differentiate them from non-certified advertising claims. One of the main practical implications of this work has to do with the critical analysis of the effectiveness of Community regulations on eco-labelling and green advertising claims.
\end{abstract}

\section{Introduction}

More and more consumers are concerned about their health and the progressive deterioration of the planet, both issues coming together in sectors such as agri-food. According to a study by [1], 85\% of millennials (those who were born between 1974 and 1997) consider "very" or "extremely important" that companies act in favor of the environment, as well as $80 \%$ of members of generation Z (born between 1998 and 2003) and 79\% of those of generation X (born between 1969 and 1983). This has been perceived by the producers, who are adapting their action guidelines accordingly. This group of stakeholders is essential to encourage responsible production, to the point of being considered the "key" element to achieve the objective of sustainability [2].

As a result, the consumption of ecological or sustainable variants of usual products is experiencing unparalleled growth. In Spain, products with an ecological seal increased by $14 \%$ in 2018 and are present in 4 out of 10 households, being consumed regularly by more

* Corresponding author: ana.lanero@,unileon.es 
than three million people (not just those who follow a specific lifestyle), their quotas reaching $20 \%$ in supermarkets and hypermarkets [3].

However, sustainable consumption is not exclusive to the most recent years, but the result of a process of advancement and consolidation. As such, the concept "formally" emerged in the second half of the 20th century, as a result of a cultural change, subsequent to modernization in Western countries [4]. It is mainly a phenomenon of developed societies in which, once the basic needs have been covered, there is a concern over issues regarding the environment, civic and personal rights and freedoms, and socio-political, intellectual, and aesthetic aspects. Consumers thus express their concern about the effects generated by their purchasing activities and issues as, for example, the origin of the products, how they are obtained, or the actors directly or indirectly involved in the manufacture of goods or the provision of services. This is a movement influenced by values such as solidarity, social responsibility, respect for human rights, multiculturalism, and ecology, as well as rationally and directly linked to the education, ethics and maturity of individuals who claim their rights through social movements, as consumer platforms or organizations. This process not only involves the consumer indeed, but also depends on the responsibility of companies and entities in the cultural and socioeconomic context of consumption [5].

Namely, after the prolonged period of recovery and growth post World War II, in which natural resources were considered unlimited and allowing an endless growth [6], in the 1970s people began to take clear awareness of the environmental problems derived from such growth patterns [7]. So "the accelerated deterioration of the environment and natural resources and the consequences for economic and social development of such deterioration" led the UN General Assembly to approve the Earth Charter in 1982 and establish the World Commission on Environment and Development in 1983 [8]. This Commission elaborated and presented to the General Assembly in 1987 the Report "Our Common Future" or the Brundtland Report ${ }^{\dagger}$, stating in its second chapter the infeasibility of the previous model of economic growth, given the scarcity of energy, materials, water and land, and the progressive costs and diminishing returns of its use, and then setting the bases of a sustainable and lasting development that makes it possible to satisfy the needs of present generations without compromising the capacity of future generations for the same purpose [9].

The recommendations in the Brundtland Report focused on three pillars: the social, economic and environmental development. These ones were divided into six common tasks to be jointly addressed to achieve sustainable development, the key element for sustainable consumption: i) stabilization of the population, while providing it with basic services and education; ii) food security (including agrarian reforms and policies that protect farmers, herders and other vulnerable groups); iii) protection of the diversity of species and ecosystems; iv) promotion of environmentally safe and economically viable energy; v) application of new technologies and regulation of discharges and waste in industry; and vi) integration of urban centers in their nearby rural areas to face the urban challenge.

\section{Responsible production and consumption as part of the Sustainable Development Goals}

Then, after other documents and resolutions, in 2015 world leaders adopted a set of global objectives as " $a$ call for action by all countries -poor, rich and middle-income- to promote prosperity while protecting the planet. They recognize that ending poverty must go hand-inhand with strategies that build economic growth and address a range of social needs including education, health, social protection, and job opportunities, while tackling climate

$\dagger$ According to the last name of the President of the Commission, the Norwegian Gro Harlem Brundtland. 
change and environmental protection" [10]. As part of a new sustainable development agenda, each one of these 17 Sustainable Development Goals (SDGs) included specific targets to be achieved within a period of 15 years until 2030, based on the collaboration of governments and public bodies, as well as private sector organizations, civil society entities and citizens.

Among the SDGs (Fig. 1), the twelfth (SDG 12) aims "to ensure sustainable consumption and production patterns", that is, "doing more and better with less. It is also about decoupling economic growth from environmental degradation, increasing resource efficiency, and promoting sustainable lifestyles". Sustainable Consumption and Production (known as SCP) is about "the use of services and related products, which respond to basic needs and bring a better quality of life while minimizing the use of natural resources and toxic materials as well as the emissions of waste and pollutants over the life cycle of the service or product so as not to jeopardize the needs of future generations" [10]. To this end, it is necessary to involve all the aforementioned interest groups and, in particular, producers/manufacturers and consumers, since it is evident that the existence of sustainable consumption in turn requires equally sustainable production.

Environmental concern regarding consumption is growing, individuals willing to use their purchasing power to positively influence the natural environment [11] or modifying their consumption habits to reduce their environmental impact and cause real change, even reaching to pay a price premium for more sustainable products. It is no longer something exclusive to privileged groups or classes, such as scuppies $\$$, but to individuals from all strata and social classes ${ }^{\S}$.
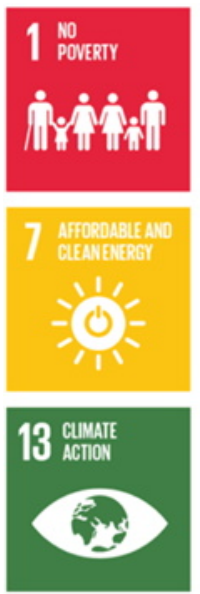
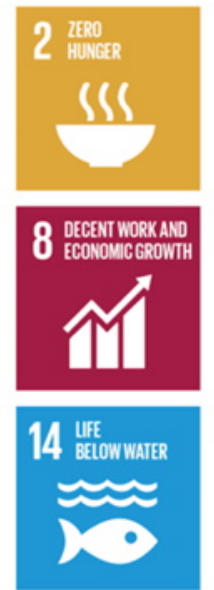
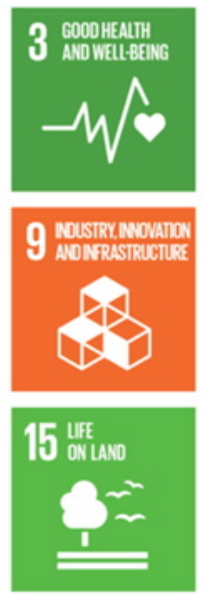
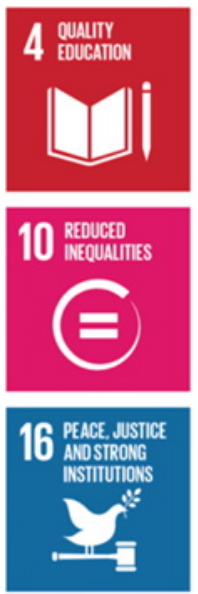
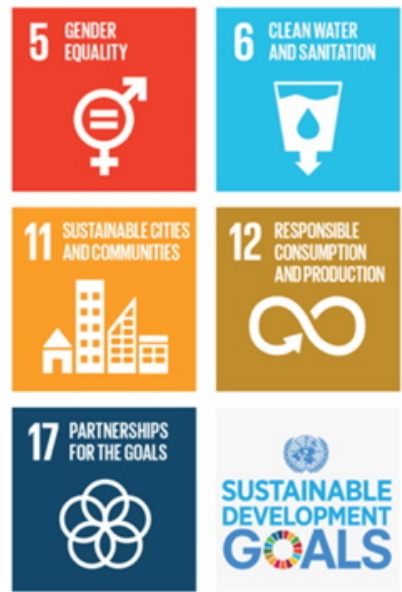

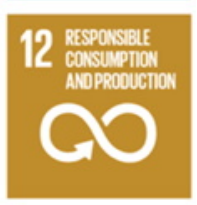

(89)

SUSTAINABLE DEVELOPMENT GEILS

Fig. 1. United Nations Sustainable Development Goals (SDGs) Source: [10]

At this purpose, as it has been pointed out, actions and commitments from brands and governments are also required, as sustainability does not only refer to the nature of the ingredients/components of a product, but it is present in the entire production process, involving issues such as the modernization of the assembly lines, the respectful behavior of the suppliers with the environment, the origin and condition of the materials that cover and

\footnotetext{
¥ A scuppie, or a Socially Conscious Upwardly-mobile Person is an individual who can afford a "green" lifestyle for peace, happiness and money (not necessarily in this order) based on above-average availability of resources [12].

$\S$ To the point of identifying the concept of sustainability and its interpretation with the imitation of nature and the epistemological transformations caused in the neoclassical economy [7].
} 
protect products, the efficient evolution of existing business models, or the CSR actions of companies. Thus, they demonstrate to the consumer that they are listened to and their needs and wants are important to them [1]. It is a type of consumption that not only leads to a good reputation for brands and companies, but benefits the buyer, the user and the planet.

\section{Third-party certified labels as an element of information for consumers}

The European Union also promotes responsibility and sustainability aiming the triple objective of economic growth, competitiveness, and social cohesion [13]. In this sense, the dominant approach is the so-called business case or economic argument [14-15], which leads to placing responsible consumption among the priorities on the political agenda [2]. In this way, the responsible consumption, that is, that consumption that takes into account the social and environmental performance of brands in its decisions, will be a necessary requirement for producers and companies to behave responsibly [16-17].

However, as indicated by [3], the business case is based on the hypothesis that the consumer wants and can buy in a responsible way, something questioned by studies that suggest that that behavior has to face motivational, cognitive and behavioral obstacles to responsible buying (and not only to the price premium that it may suppose). Among them, cognitive obstacles refer to both the lack of available information and the difficulty in locating and interpreting the available information.

One factor in this regard is how brands communicate with buyers [1], since they must transmit the benefits of their sustainable products through marketing, incorporating them, e.g., in their packaging, or through the correct use of sails, badges and labels (labelling).

In fact, some authors point out to this last possibility as the best alternative to potential failures to market asymmetries at the cognitive level [2], as allowing brands the combination of signaling (when voluntarily deciding the certification of their operations and/or the verification of their performance) and screening strategies (if a third party grants and/or monitors the badge), while labels are used by consumers as a means to locate and process information on ethical or sustainability attributes, thus transforming them into search attributes that can be judged and assessed prior to purchasing decisions [18].

Such "ethical" or "sustainable" labels can be classified based on different criteria (Table 1). For example, [19] suggested the triple criteria of environmental protection (planet care), relation to social justice (of people), or relation to animal welfare. For their part, [20] prefer to develop this classification based on the process by which they are obtained and, according to ISO regulations, they distinguish between labels or certificates granted based on processes verified by a third party (or type I), self-declarations without verification (or type II), and based on results verified by third parties (or type III).

Beyond the above and considering the identification or quality of the third party involved, [21] went into detail by distinguishing between self-awarded labels, labels granted by an industrial association or similar entity, labels granted by an NGO or non-profit entity, labels granted by multi-stakeholder coalitions, and labels granted by government agencies (or official labels).

Table 1. Classification alternatives for sustainability labels and certificates

\begin{tabular}{|c|l|c|}
\hline Criterion & \multicolumn{1}{c|}{ Categories } & Authors \\
\hline Based on content & $\begin{array}{l}\text { - Environmental protection (planet care) } \\
\text { - Social justice (caring for people) } \\
\text { - Animal welfare (animal care) }\end{array}$ & {$[19]$} \\
\hline
\end{tabular}




\begin{tabular}{|c|l|l|}
\hline $\begin{array}{c}\text { According to the way of } \\
\text { granting }\end{array}$ & $\begin{array}{l}\text { - Certification by third parties } \\
\text { - Self-declaration (without verification) } \\
\text { - Certification of results by third parties }\end{array}$ & [20] \\
\hline $\begin{array}{c}\text { - Granted by the entity itself (self-awarded) } \\
\text { According to the } \\
\text { granting entity }\end{array}$ & $\begin{array}{l}\text { - Awarded by an industrial association } \\
\text { - Awarded by an NGO or non-profit entity } \\
\text { - Awarded by a multistakeholder coalition }\end{array}$ & {$[21]$} \\
\hline
\end{tabular}

Source: Own elaboration based on [2] and the authors considered

Finally, it is important to differentiate regulated labelling from marketing advertising, because marketers sometimes use confusing claims to signal sustainability for products that do not meet any standard or certification [22]. For example, there are unregulated terms such as "natural" or "artisan" that can lead uninformed consumers to think that a product has organic properties, by wrongly considering that these are implicit in the label [23-25].

Despite the efforts invested by the European authorities in regulating the labelling of organic production, empirical evidence shows that consumers often do not have enough time and knowledge to judge the validity and meaning of the labels and claims used in the identification of organic products. Rather, they tend to resort to heuristics or simple rules that allow them to establish simple connections between product logos and their green attributes [24, 26-27].

In this sense, previous literature tends to repeatedly show that consumers tend to have quite limited knowledge about the precise meaning of third-party certified sustainability labels [28-31]. On the one hand, they present difficulties in qualifying it with respect to other commercial claims on packaging that highlight attributes not certified by third parties [24, 32-35]. On the other, they tend to confuse the meaning of different dimensions of environmental, social, and economic sustainability, understanding that the three converge in any type I certified label [36-38].

In the context of the previous review, this study is intended to analyze whether young consumers in Spain attribute organic properties to products identified by third-party certified eco-labels to the same extent that to other third-party certified sustainability labels and other non-certified organic claims.

\section{Methodology}

To respond to the research purposes, a self-report survey study was carried out in 2020 with a sample of 200 business students at the University of León, in Spain. In this way, it was guaranteed that all the participants in the study had similar knowledge regarding the control and labelling of organic products, in the context of the marketing training received in their respective degrees.

Regarding the socio-demographic characteristics of the respondents, the sample consisted of 98 women (49\%) and 102 men (51\%), with ages between 18 and 26 years, the average being 21.10 years $(D T=2.56)$.

Data collection used a collective and voluntary self-administration procedure of a questionnaire to groups of students in the context of scheduled university lectures, with the prior consent of the professor responsible in each case and in the presence of a qualified researcher for this purpose. Participants were presented with four types of type I labels and claims frequently used to identify sustainable products in Spain (Table 2):

1)the EU organic logo, which is a third-party certified label;

2)the fair-trade label certified by Fairtrade International, which identify socially responsible products; 
3)the protected geographical indication (PGI) label, which is a third-party certification of socioeconomic sustainability, and,

4)an advertising claim identifying a product as "bio" (organic).

Table 2. Type I labels and advertising claim used in the study

\begin{tabular}{|l|c|c|c|}
\hline EU organic label & Fair-trade label & PGI label & Advertising claim \\
\hline & FAIRTRADE & \\
\hline
\end{tabular}

For each type I label or advertising claim, participants were requested to report to what extent they associated them with five characteristics defining organic farming based on current European regulations [39-40], according to a Liker scale with five levels of response.

The data collected was analyzed using the SPSS 23.3 statistical program. An analysis of variance (ANOVA) was performed to verify the existence of statistically significant differences in the meaning attributed to the four labels.

\section{Results}

A one-way ANOVA was carried out, taking as an independent variable the type of label presented (EU organic logo, Fair-trade label, PGI label and advertising claim) and as dependent variable the resulting judgement of organic product associated to each logo. The results of the statistical analysis are summarized in Table 3.

Table 3. Results of ANOVA

\begin{tabular}{|c|c|c|c|}
\hline Dependent variables & Mean $(\boldsymbol{D T})$ & F & Sig. \\
\cline { 1 - 2 } EU organic label & $3.18(0.90)$ & & \\
\cline { 1 - 2 } Fair-trade label & $2.60(0.91)$ & \multirow{2}{*}{$35.62^{* * *}$} & .000 \\
\cline { 1 - 2 } PGI label & $3.13(0.83)$ & & \\
\hline Advertising claim & $3.47(0.75)$ & & \\
\hline
\end{tabular}

$* * * p<.001$

A significant effect of the type of label was obtained on the judgement of organic product, associated with a value of $F=35,62$ significant at the level of $p<.001$. In general terms, it can be seen that the respondents tended to associate more organic properties to the products identified with the advertising claim $(M=3.68)$, followed by the EU organic logo $(M=3.18)$. The PGI label obtained a similar mean score than the EU organic logo $(M=3.13)$, whereas the Fair-trade label was the least associated to environmental sustainability $(M=2.60)$.

Next, a series of post hoc analyses carried out using Tukey's HSD test allowed analyzing the differences between labels taken two by two, according to a significance level of $p<.05$. The results of this test are summarized in Table 4. Taken together, the results show that the type I EU organic label was significantly less effective than the advertising claim in helping consumers to identify a product as organic. On the other hand, consumers seemed to 
understand the meaning of the Fair-trade label, while the difference in the meaning of organic attributed to the EU organic logo and the PGI label was not statistically significant.

Table 4. HSD Post hoc analysis

\begin{tabular}{|c|c|c|c|c|}
\hline Label (I) & Label (J) & Differences (I-J) & Error & Sig. \\
\hline EU organic label & Advertising claim & $-0.29^{* *}$ & .085 & .004 \\
& Fair-trade label & $0.57^{* * *}$ & .085 & .000 \\
& PGI label & $0.05(n s)$ & .085 & .950 \\
\hline \multirow{2}{*}{ Fair-trade label } & EU organic logo & $-0,57^{* * *}$ & .085 & .000 \\
& Advertising claim & $-0.86^{* * *}$ & .085 & .000 \\
& PGI label & $-0.52^{* * *}$ & .085 & .000 \\
\hline \multirow{2}{*}{ PGI label } & EU organic logo & $-0.05(n s)$ & .085 & .950 \\
& Advertising claim & $-0.34^{* *}$ & .085 & .001 \\
& Fair-trade label & $0.52^{* * *}$ & .085 & .000 \\
\hline \multirow{2}{*}{ Advertising claim } & EU organic logo & $0.29^{* *}$ & .085 & .004 \\
& Fair-trade label & $0.86^{* * *}$ & .085 & .000 \\
& PGI label & $0.34^{* *}$ & .085 & .001 \\
\hline
\end{tabular}

$* p<.05 ; * * p<.01 ; * * * p<.001$

\section{Discussion}

This research was intended to analyze whether consumers attribute organic propertied to products identified by third-party certified eco-labels to the same extent that to other thirdparty certified sustainability labels and other non-certified organic claims. In general terms, the results of the study allow to conclude that consumers do not have a precise knowledge about the meaning of different sustainability dimensions certified by official seals, nor do they know how to differentiate them from non-certified advertising claims.

In particular, it was found that the respondents tended to attribute the same environmental sustainability to the products identified by the EU organic label as by the PGI label, despite the fact that the latter certification refers only to the social and economic sustainability of the product. In other words, although consumers seem to know how to identify those market alternatives that stand out for their greater responsibility, they do not seem to have a precise knowledge of the specific attributes to which this superiority refers. However, this effect was not extendable to the Fair-trade label, as consumers attributed a significantly lower meaning of organic product to it than to the rest of the labels and claims studied. This result can be explained by the fact that some third-party certified labels, such as the EU organic logo and the Fair-trade label, are better known to consumers, who can differentiate them better. But, in the case of lesser-known labels, uninformed consumers can reach wrong conclusions when evaluating the attributes of the products, resulting in biased purchasing decisions. Thus, although the objective of involving consumers, in this case young people, in the purchase of responsible products is achieved, this purpose is fulfilled at the cost of undermining the legitimacy of official certifications, contributing to consumers' confusion and distrust.

In addition to the above, the respondents presented significant deficiencies in the interpretation of the EU organic label, this being the most official symbol in the certification 
of organic production in Spain. Instead, they were able to attribute a better meaning to the commercial claim, in which the term "bio" is mentioned explicitly. Such results are consistent with those previously obtained by [24] and suggest the greater efficiency of the use of explicit and meaningful terms for consumers, compared to more general symbols that cannot be deciphered quickly if the individual does not have the necessary knowledge. The danger of this type of processing lies, however, in that it lends itself to favoring the purchase of products endorsed by deceptive advertising.

In sum, although young people are seduced by the green labels and claims that point to the sustainability of products, their accurate knowledge about their real meaning is quite moderate. That is to say, despite the fact that the current generations of young Spaniards are known to present high levels of environmental awareness and to be predisposed towards the purchase of organic products, the truth is that in many cases they do not have enough time and knowledge to make rational judgements on the validity of the claims and labels to which they are exposed. In these circumstances, young people represent a group especially vulnerable to the green-washing actions of many companies, which take advantage of the superficial processing that consumers make of commercial labels and use confusing claims to incite biased purchase decisions and acts [22].

One of the main practical implications of this work has to do with the critical analysis of the effectiveness of Community regulations on eco-labelling. Thus, the combined use of explicit terms and their link to an official certification body seem to be the best guarantee so that organic products can be easily identified and stimulate unbiased purchasing decisions. Likewise, there is a need to improve the regulation of the use of confusing terms that can be wrongly linked to organic production, since they lend themselves to misinterpretation by consumers who do not have appropriate knowledge.

As a limitation of the study carried out, it is worth noting the size and type of sample used, linked to a specific profile of young consumer as a university student in a certain branch of studies. New research should contrast the results obtained in this work by using broader and more diverse samples in terms of socio-demographic profile. Future studies should also expand the scope of this research, by comparing the ecological perception caused by fraudulent claims and labels and the interpretation generated by official labels.

\section{References}

1. Nielsen, Sustainable shoppers buy the change they wish to see in the world, (2018), https:// www.nielsen.com/ssa/en/insights/report/2018/sustainable-shoppers-buy-thechange-they-wish-to-see-in-the-world/, [Accessed: 19 June 2021]

2. I. Carrero Bosch, C. Valor Martínez, J.M. Rosa Durán, The relationship between the consumer and social and environmental labels. Diagnostic study to guide the definition of public policies and business action, (2010), https://www.compromisorse.com/upload/estudios/000/89/EstudioEtiquetado.pdf, [Accessed: 19 June 2021]

3. R. Villaécija, Offensive against fraud of fake bio products, El Mundo, (2019), https://www.elmundo.es/economia/ahorroyconsumo/2019/08/31/5d6948f2fdddffa2218 b465c.html, [Accessed: 19 June 2021]

4. R. Llopis Goig, Revista Española del Tercer Sector, 11, 145-165 (2009)

5. S. Dueñas Ocampo, J. Perdomo Ortiz, L.E. Villa Castaño, J. Manag. Econ. for Iberoamérica, 30(132), 287-300 (2014)

6. M.P. Weinstein, R.E. Turner, C. Ibáñez, Sustain.: Sci. Pract. Policy, 9(1), 4-15 (2013) 
7. R. Bermejo, From sustainable development according to Brundtland to sustainability as biomimesis, (Hegoa, Bilbao, 2014)

8. J. Drexhage, D. Murphy, Sustainable Development: from Brundtland to Rio 2012, Background Paper for consideration by the High Level Panel on Global Sustainability at its first meeting, 19 September 2010 (United Nations, New York, 2010).

9. WCED, Report of the World Commission on Environment and Development "Our common future" (Brundtland Report), (1987), https://undocs.org/es/A/42/427, [Accessed: 19 June 2021]

10. United Nations, Sustainable Development Goals, (2015), https://www.un.org/sustainabledevelopment/sustainable-development-goals/, [Accessed: 19 June 2021]

11. H. J. Moreno, Revista Escuela de Administración de Negocios, 77, 168-182 (2014)

12. C. Failla, The Scuppie HandbookTM. A practical guide to living well while doing good, (2008), http://www.scuppie.com/, [Accessed: 19 June 2021]

13. European Commission, Communication from the Commission concerning Corporate Social Responsibility: a business contribution to Sustainable Development (COM/2002/0347 final), (2002), https:// eur-lex.europa.eu/legalcontent/EN/TXT/?uri=celex:52002DC0347, [Accessed: 19 June 2021]

14. M. De la C. Gonzalez, C. V. Martinez, Boletín Económico de ICE, 2755, 7-20 2003.

15. D.J. Webb, L.A. Mohr, K.A. Harris, J. Bus. Res., 61(2), 91-98 2008

16. European Commission, Communication from the Commission to the European Parliament, the Council and the European Economic and Social Committee.

Implementing the partnership for growth and jobs: making Europe a pole of excellence on Corporate Social Responsibility (COM/2006/136 final), (2006), https://eurlex.europa.eu/LexUriServ/LexUriServ.do?uri=COM:2006:0136:FIN:en:PDF, [Accessed: 19 June 2021]

17. European Parliament, Report on corporate social responsibility: a new partnership (2006/2133/(INI)), (2006), https://www.europarl.europa.eu/sides/getDoc.do?pubRef=//EP//TEXT+REPORT+A6-2006-0471+0+DOC+XML+V0//EN, [Accessed: 19 June 2021]

18. A.C. Drichoutis, P. Lazaridis, R. Nayga, Acad. Mark. Sci. Rev., 9, 1-22 (2006)

19. S. Hartlieb, B. Jones, J. Bus. Ethics, 88(3), 583-600 (2009)

20. C. D’Souza, M. Taghian, P. Lamb, Corp. Commun.: Int. J., 11(2), 162-173 (2006)

21. S. Zadek, S. Lingayah, M. Forstater, Social labels: tools for ethical trade (New Economics Foundation, Brussels, 1998)

22. P. Maniatis, J. Clean. Prod., 132, 215-218 (2016)

23. R. Gifford, Int. J. Psychol., 49, 141-157 (2014)

24. J. Hoek, N. Roling, D. Holdsworth, J. Mark. Manage., 29, 772-792 (2013)

25. A. Lanero, J.L. Vázquez, C. Sahelices, Sustainability, 12(21), 1-19 (2020)

26. H.J. Kim, S.H. Lee, K. Yang, Int. J. Consum. Stud., 39, 249-260 (2015)

27. M.F. Teisl, S. Peavey, F. Newman, For. Prod. J., 52(1), 44-50 (2002)

28. P.J. Alevizou, C.J. Oates, S. McDonald, Sustainability, 7, 9729-8747 (2015)

29. C. D’Souza, M. Taghian, P. Lamb, R. Peretiatko, Int. J. Consum. Stud., 31, 371-376 (2007) 
30. L. Sirieix, M. Delanchy, H. Remaud, L. Zepeda, P. Gurviez, Int. J. Consum. Stud., 37, 143-151 (2013)

31. K.M.R. Taufique, C. Siwar, B. Talib, F.H. Sarah, N. Chamhuri, Sustainability, 6, 2176-2200 (2014)

32. C. Amos, J.C. Hansen, S. King, J. Consum. Mark., 36(4), 516-526 (2019)

33. N. Darnall, H. Ji, D.A. Vázquez-Brust, J. Bus. Ethics, 150, 953-969 (2018)

34. P. Fanasch, B. Frick, J. Clean. Prod., 249, 1-16 (2020)

35. U.J.J. Hahnel, O. Arnold, M. Waschto, L. Korcaj, K. Hillmann, D. Roser, H. Spada, Front. Psychol., 6, 1-17 (2015)

36. V. Gruber, B.B. Schlegelmilch, M.J. Houston, Psychol. Mark., 31(6), 440-450 (2014)

37. G.A. Lazzarrini, V.H.M. Visschers, M. Siegrist, Food quality and preference, 60, $165-$ 177 (2017)

38. S. Rousseau, Food Quality and Preference, 44, 92-100 (2015)

39. Regulation EU 2012/1151 of the European Parliament and of the Council of 21 November 2012 on quality schemes for agricultural products and foodstuffs, OJEU, L 343, 1-29 (Dec. 2012)

40. Regulation (EU) 2018/848 of the European Parliament and of the Council of 30 May 2018 on organic production and labelling of organic products and repealing Council Regulation (EC) No 834/2007, OJEU, L 150, 1-92 (June 2018) 